\title{
Apparent Influence of the X Chromosome on Timing of 73 Ossification Centers
}

\author{
STANLEY M. GARN, CHRISTABEL G. ROHMANN \\ AND KEITH P. HERTZOG ${ }^{1}$ \\ Center for Human Growth and Development, University of Michigan, \\ Ann Arbor, Michigan; The Fels Research Institute, \\ Yellow Springs, Ohio
}

\begin{abstract}
Among 73 postnatal ossification centers, sister-sister (SS) corretions involving age at appearance tend to exceed brother-brother (BB) and sisterbrother (SB) correlations by an average of 0.16 . This excess of SS over BB and SB ossification timing similarity is not a function of type of center, limb ox location, and is in accordance with the hypothesis of partial X-linkage. It is estimated that the larger proportion of genetically determined variance in postnatal ossification timing may be attributed to genes on the $\mathrm{X}$ chromosome.
\end{abstract}

There is now considerable evidence for partial X-chromosomal involvement in postnatal developmental timing. This we first found for the teeth (Garn, Lewis and Polacheck, '60; Garn and Rohmann, '62a; Garn, Lewis and Kerewsky, '65a,b) and later for postnatal hand-wrist timing (Garn and Rohmann, '62b; Garn, Rohmann and Davis, '63). Consistently, sisters show a higher communality in postnatal ossification timing than is true for either brother-sister or brother-brother pairs, and father-daughter similarities in postnatal ossification timing exceed father-son, mother-son, and mother-daughter hand-wrist timing resemblances. In toto, this evidence is consistent with the hypothesis of X-chromosomal involvement, the excess of sister-sister over brother-brother similarity coefficients indicating the relative contribution of genes on the $\mathrm{X}$ chromosomes and those on the remaining autosomes.

In the present study we have newly extended data analysis to encompass all available postnatal ossification centers of the hand, foot, elbow, knee, shoulder, and hip (including the adductor sesamoid of the thumb) and covering the age range 1 month through 15 years in age at appearance. Sister-sister, sister-brother and brother-brother similarity coefficients have been calculated center by center and then pooled in order to provide the best possible estimates of sex-specific and cross-sex similarities in postnatal ossification timing.

\section{METHODS AND MATERIALS}

This study is based on the magnitude of sibling resemblances in the age at appearance of 73 postnatal ossification centers as ascertained from serial, longitudinal radiographs of long-term participants in studies of growth and aging. In every instance the age at appearance of a given postnatal ossification center was verified by reference to previous and succeeding radiographs and no value was reported where there was ambiguity because of subject postioning, radiographic quality, or missed visits. The approach, radiographic analysis and analytical techniques are those previously described by us, particulary in Garn, Rohmann and Blumenthal ('66) and Garn, Rohmann and Silverman ('67).

Raw scores for age-at-appearance were first converted into sex-specific normalized T-scores, following McCall's method, and employing the machine program described by Black ('66). This procedure effectively eliminated the effects of skewness inherent in dichotomous growth data. For further details see Garn and Shamir ('58), Lacey ('56) and Black ('66).

Separate correlations were made for (a) sisters, (b) brothers and (c) cross-sexed sibling pairs, so as to test for possible influences of the $\mathrm{X}$ and $\mathrm{Y}$ chromosomes. Mean values of $r$ were also computed for

1 Present address: University of Pennsylvania, Department of Anthropology, Philadelphia, Pennsylvania. 
73 ossification correlations for each type of comparison (SS, BB and BS) and for all 219 correlations, both after weighting for sample size and, separately using unweighted values. Throughout, mean values of $r$ were calculated from the corresponding $z$ transforms of $r$ as described by Fisher ('58).

Further data analysis included grouping by (1) type of center (i.e., round bones, metacarpal and metatarsal epiphyses etc.) and (2) by age at appearance, in order to explore differential genetic effects on (a) type of center and location or (b) sequence in the total pattern of postnatal ossification. Finally, an attempt was made to apportion sex-chromosomal and autosomal influences by comparison of mean values of $r$ for sister pairs and brothers pairs respectively.

\section{Findings}

In the first step of the data analysis, sister-sister, sister-brother and brotherbrother age-at-ossification correlations were tabulated, center by center. With a total of 73 postnatal ossification centers considered, this amounted to 219 correlations, and 8256 ossification center pairings in all. Whether pooled as the mean unweighted $r$ for all 73 correlations for each type of sibling pairing, or when employing the mean $r$ from the mean $z$ transform of $r$, the results were then in the same direction. Sister-sister correlations were the highest (mean $r=0.49$ and 0.52 respectively) and considerably exceeded sister-brother correlations ( 0.36 and 0.38 respectively) which were slightly higher than brotherbrother correlations $(0.32$ and 0.35$)$. Overall, sister-sister (SS) ossification correlations approximated 0.5 , sister-brother correlations approximated 0.37 and brother-brother correlations 0.33 . The rankings were then $r_{\mathrm{BS}}>r_{\mathrm{SB} / \mathrm{BB}}$.

Much the same picture emerged from a center-by-center comparison, and use of a sign test. Overall, SS ossification-timing correlations were higher than the corresponding SB correlations for 51.5 centers $\left(x^{2}=12.3\right)$ and higher than the corresponding BB correlations for 49.5 centers $\left(x^{2}=9.3\right) .^{2}$ Though exact tests of significance are not practicable, because postnatal ossification centers are positively if often slightly correlated, and because of re- peated sampling from the same population sample, the trend is nevertheless clear. Sisters are appreciably more similar in postnatal ossification timing than either brothers or brother-sister pairs.

In the second step of the analysis the correlations were arrayed according to (1) type of center, (2) location on the body frame, and (3) age at appearance, in order to explore anatomical and timing variables. Arrangement as to type of center provided no particular illumination. As shown in table 2, round bones, epiphyses of the long bones, metacarpal epiphyses etc. generally followed the SS $>$ SB $/ B B$ rule. Similarly, comparison of the upper and lower limbs provided no surprises, except to indicate their overall similarity despite the assumption of the upright posture. Analysis in terms of timing (i.e. age at appearance) proved more valuable, however.

Breaking the data into three cycles $(0.00-0.99$ years, $1.00-9.99$, and $10.00-$ $\mathrm{X}$ years) did prove revealing. Using the 3cycle approach, since percent sexual dimorphism in postnatal ossification timing does, in fact, fit a 3-cycle plot (cf. Garn, Rohmann and Silverman, '67), the present data also provided a useful fit. For centers 1 through 10 ( 0.0 to 0.8 years) the excess of SS over BB was only 0.04 . For centers 11 through 65 ( 1.0 to 9.7 years) it was 0.11 , and for centers $66-73$ (11.2 through 15.3 years) the excess of SS over BB ossification correlations was then greater than 0.50 . In a general way, then, the hypothesis of X-chromosomal involvement is most tenable for the centers of ossification that appear well after the first year of life.

Since SS $>$ SB $/ B B$ it is then possible to make some numerical estimate of the relative involvement of the $\mathrm{X}$ chromosome. This can be done under the assumption that $r_{B B}$ represents both the autosomal contribution and that of one X chromosome, while $r_{\mathrm{ss}}$ represents the further contribution of the paternal X chromosome. Since $r_{\text {ss }}$ approximates 0.51 , while $r_{B B}$ approximates 0.33 , as mentioned above, the relative contribution of the paternal X chromosome to total interpersonal variance may then be estimated as 0.15 , i.e. $0.51^{2}-0.33^{2}$. Since all genes in common account for approximately $25 \%$ of timing variance in these

\footnotetext{
2 Including tied values.
} 
TABLE 1

Sister-sister, sister-brother and brother-brother similarities in ossification timing

\begin{tabular}{|c|c|c|c|c|c|c|c|}
\hline \multirow{2}{*}{\multicolumn{2}{|c|}{ Ossification center }} & \multicolumn{2}{|c|}{ Sister-sister } & \multicolumn{2}{|c|}{ Sister-brother } & \multicolumn{2}{|c|}{ Brother-brother } \\
\hline & & $\mathbf{N}$ & $\boldsymbol{r}$ & $\mathbf{N}$ & $r$ & $\mathbf{N}$ & $\boldsymbol{r}$ \\
\hline 1 & Head of humerus & 7 & 0.09 & 23 & 0.69 & 12 & 0.69 \\
\hline 2 & Proximal epiphysis, tibia & 13 & .00 & 33 & .28 & 20 & .55 \\
\hline 3 & Coracoid proc., scapula & 2 & .00 & $\mathbf{5}$ & -.25 & 1 & .00 \\
\hline 4 & Cuboid & 31 & -.05 & 55 & -.09 & 39 & .04 \\
\hline 5 & Capitate & 22 & .05 & 64 & -.05 & 36 & -.06 \\
\hline 6 & Hamate & 23 & .18 & 65 & .04 & 35 & -.02 \\
\hline 7 & Capitellum of humerus & 14 & .58 & 55 & .38 & 35 & .46 \\
\hline 8 & Head of femur & 16 & .61 & 50 & .47 & 37 & .18 \\
\hline 9 & Lateral cuneiform & 10 & .79 & 39 & .05 & 29 & -.07 \\
\hline 10 & Greater tuberosity - humerus & 10 & .72 & 28 & .15 & 9 & .84 \\
\hline 11 & Primary center, middle phalanx, 5 th toe & 15 & .42 & 54 & .56 & 39 & .51 \\
\hline 12 & Distal epiphysis, radius & 29 & .71 & 76 & .44 & 42 & .34 \\
\hline 13 & Epiphysis, distal phalanx, 1st toe & 14 & .66 & 52 & .46 & 33 & .47 \\
\hline 14 & Epiphysis, middle phalanx, 4 th toe & 6 & .17 & 18 & .39 & 13 & .47 \\
\hline 15 & Epiphysis, prox. phalanx, 3rd finger & 28 & .52 & 74 & .15 & 44 & .20 \\
\hline 16 & Epiphysis, middle phalanx, 3rd toe & 13 & .28 & 43 & .03 & 26 & .37 \\
\hline 17 & Epiphysis, prox. phalanx, 2nd finger & 30 & .66 & 77 & .28 & 44 & .32 \\
\hline 18 & Epiphysis, prox. phalanx, 4th finger & 31 & .65 & 73 & .18 & 42 & .33 \\
\hline 19 & Epiphysis, distal phalanx, 1st finger & 30 & .39 & 77 & .39 & 43 & .28 \\
\hline 20 & Epiphysis, prox. phalanx, 3rd toe & 15 & .69 & 60 & .40 & 36 & .21 \\
\hline 21 & Epiphysis, 2nd metacarpal & 32 & .53 & 77 & .37 & 41 & .19 \\
\hline 22 & Epiphysis, prox. phalanx, 4 th toe & 16 & .92 & 58 & .34 & 33 & .19 \\
\hline 23 & Epiphysis, prox, phalanx, 2nd toe & 17 & .65 & 58 & .43 & 35 & .46 \\
\hline 24 & Epiphysis, 3rd metacarpal & 32 & .52 & 79 & .42 & 41 & .41 \\
\hline 25 & Epiphysis, prox. phalanx, 5th finger & 35 & .36 & 87 & .43 & 44 & .46 \\
\hline 26 & Epiphysis, middle phalanx, 3rd finger & 30 & .41 & 78 & .47 & 43 & .45 \\
\hline 27 & Epiphysis, 4th metacarpal & 34 & .44 & 77 & .54 & 43 & .43 \\
\hline 28 & Epiphysis, middle phalanx, 2nd toe & 16 & .60 & 55 & .49 & $\mathbf{3 4}$ & .58 \\
\hline 29 & Epiphysis, middle phalanx, 4 th finger & 29 & .46 & 79 & .38 & 43 & .34 \\
\hline 30 & Epiphysis, 5th metacarpal & 35 & .36 & 80 & .49 & 46 & .40 \\
\hline 31 & Medial cuneiform & 18 & .58 & 53 & .45 & 31 & .18 \\
\hline 32 & Epiphysis, 1st metatarsal & 20 & .65 & 60 & .02 & 34 & .39 \\
\hline 33 & Epiphysis, middle phalanx, 2nd finger & 30 & .57 & 79 & .54 & 48 & .59 \\
\hline 34 & Epiphysis, prox. phalanx, 1st toe & 20 & .72 & 54 & .39 & 33 & .34 \\
\hline 35 & Epiphysis, distal phalanx, 3rd finger & 29 & .42 & 77 & .43 & 45 & .29 \\
\hline 36 & Triquetral & 35 & .47 & 79 & .34 & 49 & .30 \\
\hline 37 & Epiphysis, distal phalanx, 4th finger & 31 & .31 & 80 & .51 & 47 & .42 \\
\hline 38 & Epiphysis, prox. phalanx, 5th toe & 20 & .45 & 58 & .27 & 35 & .22 \\
\hline 39 & Epiphysis, 1st metacarpal & 35 & .36 & 99 & .55 & 57 & .44 \\
\hline 40 & Intermediate (middle) cuneiform & 22 & .68 & 53 & .49 & 30 & .28 \\
\hline 41 & Epiphysis, 2nd metatarsal & 20 & .55 & 53 & .39 & 28 & .09 \\
\hline 42 & Greater trochanter & 28 & .47 & 66 & .21 & 35 & .50 \\
\hline 43 & Epiphysis, prox. phalanx, 1st finger & 36 & .36 & 95 & .37 & 52 & .38 \\
\hline 44 & Navicular of foot & 21 & .42 & 56 & .50 & 29 & .61 \\
\hline 45 & Epiphysis, distal phalanx, 2nd finger & 40 & .57 & 100 & .47 & 53 & .39 \\
\hline 46 & Epiphysis, distal phalanx, 5th finger & 39 & .37 & 95 & .47 & 56 & .30 \\
\hline 47 & Epiphysis, middle phalanx, 5 th finger & 36 & .60 & 90 & .44 & 51 & .26 \\
\hline 48 & Proximal epiphysis of fibula & 18 & .21 & 52 & .28 & 25 & .16 \\
\hline & Epiphysis, 3rd metatarsal & 23 & .53 & 55 & .42 & 26 & .42 \\
\hline & Epiphysis, distal phalanx, 5th toe & 16 & .18 & 30 & -.03 & 21 & .54 \\
\hline & Patella & 12 & .90 & 39 & .75 & 25 & .88 \\
\hline & Epiphysis, 4th metatarsal & 23 & .59 & 55 & .37 & 26 & .28 \\
\hline 53 & Lunate & 37 & .66 & 89 & .60 & 47 & .39 \\
\hline & Epiphysis, distal phalanx, 3rd toe & 21 & .07 & 51 & .45 & 26 & .56 \\
\hline & Epiphysis, 5th metatarsal & 24 & .68 & 50 & .46 & 26 & .38 \\
\hline & Epiphysis, distal phalanx, 4th toe & 21 & -.00 & 53 & .32 & 26 & .54 \\
\hline & Epiphysis, distal phalanx, 2nd toe & 22 & .21 & 51 & .32 & 26 & .52 \\
\hline & Capitulum of radius & 17 & .66 & 54 & .54 & 33 & .31 \\
\hline & Navicular of hand (scaphoid) & 37 & .61 & 70 & .51 & 41 & .35 \\
\hline & Trapezium & 38 & .77 & 77 & .44 & 41 & .41 \\
\hline & Trapezoid & 38 & .62 & 76 & .58 & 44 & .40 \\
\hline & Medial epicondyle of humerus & 17 & .33 & 53 & .44 & 33 & .47 \\
\hline
\end{tabular}


TABLE 1 (continued)

Sister-sister, sister-brother and brother-brother similarities in ossification timing

\begin{tabular}{|c|c|c|c|c|c|c|c|}
\hline \multirow{2}{*}{\multicolumn{2}{|c|}{ Ossification center }} & \multicolumn{2}{|c|}{ Sister-sister } & \multicolumn{2}{|c|}{ Sister-brother } & \multicolumn{2}{|c|}{ Brother-brother } \\
\hline & & $\mathbf{N}$ & $\boldsymbol{r}$ & $\mathbf{N}$ & $r$ & $\mathbf{N}$ & $r$ \\
\hline \multirow{3}{*}{\multicolumn{2}{|c|}{$\begin{array}{l}\text { 63. Distal epiphysis of ulna } \\
\text { 64. Epiphysis of calcaneus } \\
\text { 65. Olecranon process of ulna } \\
\text { 66. Lateral epicondyle of humerus } \\
\text { 67. Tibia tubercle } \\
\text { 68. Adductor sesamoid of thumb } \\
\text { 69. Os acetabulum } \\
\text { 70. Acromial process } \\
\text { 71. Epiphysis of iliac crest } \\
\text { 72. Accessory epiphysis, coracoid proc. } \\
\text { 73. Ischial tuberosity } \\
\text { Mean unweighted } r \\
\text { Mean unweighted } r \text { from } z \text { transform of } r\end{array}$}} & $\begin{array}{r}27 \\
20 \\
18 \\
24 \\
15 \\
23 \\
9 \\
9 \\
7 \\
9 \\
5\end{array}$ & $\begin{array}{l}.68 \\
.55 \\
.84 \\
.60 \\
.74 \\
.59 \\
.71 \\
.03 \\
.80 \\
.53 \\
.76\end{array}$ & $\begin{array}{l}68 \\
43 \\
42 \\
48 \\
24 \\
58 \\
14 \\
28 \\
17 \\
23 \\
13\end{array}$ & $\begin{array}{r}.48 \\
.44 \\
.54 \\
.32 \\
.31 \\
-.05 \\
.43 \\
.13 \\
.31 \\
.45 \\
.52\end{array}$ & $\begin{array}{r}37 \\
22 \\
19 \\
20 \\
11 \\
35 \\
4 \\
15 \\
6 \\
12 \\
4\end{array}$ & $\begin{array}{r}.37 \\
.36 \\
.52 \\
.34 \\
-.24 \\
.36 \\
.09 \\
.10 \\
-.43 \\
-.19 \\
-.58\end{array}$ \\
\hline & & 1645 & 0.490 & 4229 & 0.362 & 2382 & 0.319 \\
\hline & & & 0.527 & & 0.376 & & 0.350 \\
\hline
\end{tabular}

TABLE 2

Sibling similarities in ossification timing by type of center

\begin{tabular}{lcccc}
\hline \multicolumn{1}{c}{ Type of center } & $\begin{array}{c}\text { Sister- } \\
\text { sister } \\
\text { mean } r\end{array}$ & $\begin{array}{c}\text { Sister- } \\
\text { brother } \\
\text { mean } r\end{array}$ & $\begin{array}{c}\text { Brother- } \\
\text { brother } \\
\text { mean } r\end{array}$ & $\begin{array}{c}\text { All } \\
\text { pairings } \\
\text { mean } r\end{array}$ \\
\hline Round bones & 0.48 & 0.32 & 0.23 & 0.36 \\
Epiphyses of long bones & 0.50 & 0.35 & 0.23 & 0.35 \\
Epiphyses of metacarpals & 0.44 & 0.48 & 0.37 & 0.43 \\
Epiphyses of metatarsals & 0.60 & 0.33 & 0.31 & 0.41 \\
Epiphyses of proximals & 0.60 & 0.32 & 0.31 & 0.41 \\
Epiphyses of middles & 0.44 & 0.40 & 0.43 & 0.42 \\
Epiphyses of distals & 0.32 & 0.38 & 0.43 & 0.38 \\
\hline
\end{tabular}

sister-sister comparisons, there is then reason to believe that the greater part of genetically determined variance in postnatal ossification timing may have an $X$ chromosomal basis, certainly in the female and probably in the male as well.

Postnatal ossification timing of 73 centers of the hand-wrist, foot-ankle, elbow, knee, shoulder and hip thus shows sibling resemblances of 0.30 to 0.50 with a notable excess of sister (SS) similarity over brother-sister (BS) and brother-brother (BB) similarity. From the numerical data there is the not unreasonable suggestion that genes on the $\mathrm{X}$ chromosomes have somewhat more influence on postnatal ossification timing than genes on the remaining autosomes.

\section{DISCUSSION}

The findings in this particular study are simple to summarize. Sister-sister (SS) correlations in postnatal ossification timing generally exceed sister-brother (SB) and brother-brother (BB) correlations, and these systematic differences are suggestive of X-chromosomal involvement. With some differences associated with the three cycles of age at ossification, with few consistent differences attributable to type of center or anatomical location, and with individual values of $r$ subject to sampling fluctuations, one generalization is indeed clear. Overall, for 73 postnatal bony nuclei, appearing over a 15 year span, SS correlations approximate $0.51, \mathrm{SB}$ correlations average close to 0.37 , and $\mathrm{BB}$ correlations nearer 0.33 .

These data, supported by relevant parent-child similarities in postnatal ossification timing, are consistent with the hypothesis of autosomal plus X-linked inheritance. As a first approximation, the relative involvement of autosomal genes and genes on the $\mathrm{X}$ chromosome can be ascertained by the comparison of fatherdaughter and father-son similarities, since the latter pairing shares no $\mathrm{X}$ chromosomes 
in common. (This is also true of the sons of brothers.) As a second approximation, sister-sister and brother-brother comparisons provide some indication, for sisters share the paternal $X$ and have a 50:50 chance of sharing the same maternal $X$ chromosome in common.

In the order $\mathrm{SS}>\mathrm{SB} / \mathrm{BB}$, postnatal ossification resembles postnatal tooth formation (Garn, Lewis and Polacheck, '60; Garn and Rohmann, '62a; Garn, Lewis and Kerewsky, ' $65 a, b$ ) for the same population sample. Moreover, again for the same population sample, crown-size dimensions (mesiodistal and buccolingual) also show an excess of SS over SB and BB correlations (cf. Garn et al., '67), a finding that has been substantiated by Lewis and Grainger ('67) for Burlington, Ontario, children and by Goose ('67) for a Liverpool, England, sample. Further, in our still unpublished data on tibial length from birth to maturity, and for statural data, SS again exceeds SB and BB. It would appear, therefore, that the phenomenon of partial $X$ linkage, or better the partial influence of the $\mathrm{X}$ chromosome, is common to many developmental features.

Estimating the relative influence of genes on the $\mathrm{X}$ chromosome and of autosomal genes is admittedly hazardous. Analytical errors tend to attenuate product moment correlations, and both maternal effects and postnatal nutritional effects tend to raise them. However, if sisters sharing the paternal $X$ exceed brothers by 0.14 to 0.16 (see above) then the relative combination of at least one $X$ chromosome can be estimated as $(0.51)^{2}-(0.33)^{2}$ or 0.15 . By this method of computation it would appear that $\mathrm{X}$ chromosomal involvement is at least as large as that of the autosomes in determining brother-brother resemblance and that the $\mathrm{X}$ chromosome (or rather the $X$ chromosomes) together account for the major portion of genetically-determined timing variance or postnatal ossification.

Further, however, the raw-order correlations given in the first table tend to suggest a degree of uniformity that would not, in fact, occur under the assumption of partial X-linkage. With the choice of one of a pair of maternal X chromosomes one set of brothers could be much alike in postnatal ossification and another pair (of the same parentage) quite unalike both in tempo and pattern of ossification. ${ }^{3} \mathrm{Fi}$ nally, the far greater similarity of sisters than brothers by virtue of the additional paternal X chromosome shared in common should extend itself to monozygotic twins, with single egg girl twins then being quantitatively more alike than boy twins. As with further attention to parent-child ossification timing similarities and those of male fraternal cousins, comparison of male and female single-egg twins should further illuminate the role of the $\mathrm{X}$ chromosome in ossification.

\section{ACKNOWLEDGMENTS}

The research reported in this paper was supported by grant AM 13378-01 from the National Institutes of Health and includes age-at-appearance analyses completed by Thomas Blumenthal and Claire $S$. Kaplan and computer analyses conducted under FR-00222 under the direction of Guido Wernicke and the assistance of Mae Eyman. This paper was completed by Betty Wagner.

\section{LITERATURE CITED}

Black, C. R. 1966 A computer approach to the parametric and non-parametric description of distributions and their subsequent noramlization using a polynomial to obtain normalized $T$ scores. Ann. N. Y. Acad. Sci., 134: 538-540.

Garn, S. M., A. B. Lewis and R. S. Kerewsky 1965a Genetic, nutritional, and maturational correlates of dental development. J. Dent. Res., 44: 228-242.

$1965 \mathrm{~b} X$-linked inheritance of tooth size. J. Dent. Res., 44: 439-441.

Garn, S. M., A. B. Lewis and D. L. Polacheck 1960 Sibling similarities in dental development. J. Dent. Res., 39: 170-175.

Garn, S. M., A. B. Lewis, D. Swindler and R. S. Kerewsky 1967 Genetic control of sexual di. morphism in tooth size. J. Dent. Res. Supplement (A. A. Dahlberg, ed.), 46: 963-972.

Garn, S. M., A. B. Lewis and A. J. Walenga 1968 Evidence for a secular trend in tooth size over two generations. J. Dent. Res., 47: 503.

Garn, S. M., and C. G. Rohmann 1962a Xlinked inheritance of developmental timing in man. Nature, 196: 695-696.

$1962 b$ Parent-child similarities in handwrist ossification. Am. J. Dis. Child., 103: 603607.

${ }^{3}$ Since fathers and sons share no $X$ chromosomes in common, the assumption of X-linkage affords the possibility of relatively large intergenerational difpossibility of relatively large intergenerational difsize (cf. Garn, Lewis and Walenga, '68). 
Garn, S. M., C. G. Rohmann and T. Blumenthal 1966 Ossification sequence polymorphism and sexual dimorphism in skeletal development. Am. J. Phys. Anthrop., 24: 101-115.

Garn, S. M., C. G. Rohmann and A. A. Davis 1963 Genetics of hand-wrist ossification. Am. J. Phys. Anthrop., 21: 33-40.

Garn, S. M., C. G. Rohmann and F. N. Silverman 1967 Radiographic standards for postnatal ossification and tooth calcification. Med. Radiogr. Photogr., 43: 45-66.
Garn, S. M., and Z. Shamir 1958 Methods for Research in Human Growth. Charles C Thomas, Springfield, Illinois.

Goose, D. H. 1967 Preliminary study of tooth size in families. J. Dent. Res., 46: 959-962.

Lacey, J. I. 1956 The evaluation of autonomic responses: toward a general solution. Ann, N. Y. Acad. Sci., 67: 144-150.

Lewis, D. W., and R. M. Grainger 1967 Sexlinked inheritance of tooth size: a family study. Arch. Oral Biol., 12: 539-544. 